\title{
Is presentation of ADHD subtypes different between community and clinical samples?
}

\section{Letter to the Editor}

$\mathrm{I}$ read with interest the letter by Ramelli et al ${ }^{[1]}$ They reported that the presentation of attention deficit hyperactivity disorder (ADHD) subtypes are age dependent. Herein, I would like to mention the results of similar published studies about association of ADHD subtype and children's age.

A study on a clinical sample of 171 (79.5\% boys and $20.5 \%$ girls) children and adolescents with ADHD with the age range of 5.5 to 18 years indicated that the mean age of children with ADHD-predominantly hyperactive impulsive types was significantly lower than that of the other subtypes. Also, the mean age of the children with inattentive types of ADHD was higher than that of the other two subtypes. However, after considering gender as a covariant factor, there was no association between ADHD subtypes and age. ${ }^{[2]}$

Another study on 380 clinic-referred youths aged 4-17 years reported that the symptoms of hyperactivityimpulsivity symptoms present earlier in preschool children while the inattentive type of ADHD is more common in adolescents. ${ }^{[3]}$

Of course, both of these studies are from clinical samples. Even, they do not seem to represent clinical samples of children from the world. Children with ADHD who are referred to clinics usually suffer from severe form of the disorder. Also, most of the clinical samples of children with ADHD suffer from other comorbid psychiatric disorders. ${ }^{[4]}$ Therefore, further studies on community samples of children with ADHD considering covariant factors should be conducted to find whether presentation of ADHD subtypes is age dependent.

\section{Ahmad Ghanizadeh, MD}

Research Center for Psychiatry and Behavioral Sciences, Department of Psychiatry, Shiraz University of Medical Sciences, Hafez Hospital,

Shiraz, Iran

Email:ghanizad@sina.tums.ac.ir

\section{References}

1 Ramelli GP, Zanda N, Bianchetti MG, Leoni F. Age-dependent presentation in children with attention deficit hyperactivity disorder. World J Pediatr 2010;6:90.

2 Ghanizadeh A. Psychiatric comorbidity differences in clinicreferred children and adolescents with ADHD according to the subtypes and gender. J Child Neurol 2009;24:679-684.

3 Lahey BB, Applegate B, McBurnett K, Biederman J, Greenhill L, Hynd GW, et al. DSM-IV field trials for attention deficit hyperactivity disorder in children and adolescents. Am J Psychiatry 1994;151:1673-1685.

4 Ghanizadeh A, Mohammadi MR, Moini R. Comorbidity of psychiatric disorders and parental psychiatric disorders in a sample of Iranian children with ADHD. J Atten Disord 2008; 12:149-155. 